\title{
Association of bruxism and anxiety symptoms among military firefighters with frequent episodic tension type headache and temporomandibular disorders
}

\author{
Associação de bruxismo e sintomas de ansiedade em bombeiros militares com cefaleia \\ do tipo tensional episódica frequente e desordens temporomandibulares.
}

Bianca de Araújo WAGNER', Pedro Ferreira MOREIRA FILHO²,3, Vagner Gonçalves BERNARDO4,5

\begin{abstract}
Objective: To assess the presence of bruxism and anxiety among military firefighters with frequent episodic tension-type headache and painful temporomandibular disorders (TMDs). Methods: The sample consisted of 162 individuals aged 18 to 55 years divided into four groups. Headache was diagnosed in accordance with the International Classification of Headache Disorders-III. The Research Diagnostic Criteria for Temporomandibular Disorders questionnaire was used to classify TMDs and awake bruxism; sleep bruxism was diagnosed in accordance with the International Classification of Sleep Disorders-3; and anxiety was classified using the Beck Anxiety Inventory. In statistical models, a significance level of $95 \%$ was used. The chi-square test was used to assess anxiety. Results: Associations were found among frequent episodic tension-type headache, painful TMDs, awake bruxism and anxiety $(p<0.0005)$. Sleep bruxism was not a risk factor $(p=0.119)$ except when associated with awake bruxism $(p=0.011)$. Conclusion: Anxiety and awake bruxism were independent risk factors for developing frequent episodic tension-type headache associated with painful TMDs; only awake bruxism was a risk factor for frequent episodic tension-type headache with non-painful TMDs.
\end{abstract}

Keywords: Tension-type headache; temporomandibular joint disorders; bruxism; anxiety.

\section{RESUMO}

Objetivo: Avaliar a presença de bruxismo e sintomas de ansiedade entre bombeiros militares com cefaleia do tipo tensional episódica frequente (CTTEF) e desordens temporomandibulares Dolorosas (DTMs). Métodos: A amostra foi composta por 162 indivíduos com idade entre 18 e 55 anos divididos em quatro grupos. A CTTEF foi diagnosticada de acordo com o ICHD-III. O RDC / TMD foi usado para classificar as DTMs e o bruxismo acordado; o bruxismo do sono foi diagnosticado de acordo com o ICSD-3; e a ansiedade foi classificada usando o Inventário de Ansiedade de Beck. Nos modelos estatísticos, utilizou-se um nível de significância de 95\%. O teste Qui-quadrado avaliou a ansiedade. Resultados: Associações foram encontradas entre CTTEF, DTMs dolorosas, bruxismo diurno e ansiedade ( $p<0,0005)$. 0 bruxismo do sono não foi fator de risco ( $p=0,119)$, mas quando associado à atividade diurna $(p=0,011)$. Conclusão: Ansiedade e bruxismo diurno foram fatores de risco independentes para o desenvolvimento de CTTEF associado a DTMs dolorosas. Apenas o bruxismo diurno foi fator de risco para CTTEF com DTMs não dolorosas.

Palavras-chave: Cefaleia do tipo tensional; Desordens da articulação temporomandibular; bruxismo; ansiedade.

Studies have indicated that the activities of military firefighters have direct correlations with occupational stress, high risk of back injuries, dangerous working conditions, complaints of anxiety and irregular work shifts ${ }^{1,2,3}$.

\footnotetext{
'Universidade Federal Fluminense, Faculdade de Medicina, Pós-graduação em Neurociências, Niterói RJ, Brasil;

${ }^{2}$ Corpo de Bombeiros Militar do Estado do Rio de Janeiro, Rio de Janeiro RJ, Brasil;

${ }^{3}$ Universidade Federal Fluminense, Faculdade de Medicina, Departamento de Neurologia, Niterói RJ, Brasil;

${ }^{4}$ Universidade Federal Fluminense, Patologia Oral, Niterói RJ, Brasil;

${ }^{5}$ Instituto Nacional do Câncer, Departamento de Oncologia, Rio de Janeiro RJ, Brasil.
}

Bianca de Araújo Wagner (iD https://orcid.org/0000-0003-3133-7143;Vagner Gonçalves Bernardo iD https://orcid.org/0000-0003-2844-0924; Pedro Ferreira Moreira Filho iD https://orcid.org/0000-0003-2449-428X

Correspondence: Bianca de Araújo Wagner; Universidade Federal Fluminense; Praça Carlos Gardel, 32 / apto 301 - Recreio; 22790 -460 Rio de Janeiro RJ, Brasil; E-mail: biancawagner@gmail.com;

Conflict of interest: There is no conflict of interest to declare.

Received 23 October 2018; Received in final form 08 April 2019; Accepted 13 April 2019. 
The exact mechanisms of tension-type headache are unknown. Peripheral pain mechanisms are most likely to play a role in frequent episodic tension-type headache. Increased pericranial tenderness recorded by manual palpation is the most significant abnormal finding in patients with tensiontype headache ${ }^{4}$.

Tension-type headaches have been poorly studied and perhaps neglected in relation to other primary headaches ${ }^{5}$ because of the low demand for care at study centers for headache treatment. However, when these are seen in association with temporomandibular disorders (TMDs), the demand for treatment in orofacial pain centers is significant and, often, the overlapping of symptoms makes diagnosis difficult ${ }^{6}$.

Symptoms of anxiety have been correlated with the presence of headaches ${ }^{7,8,9}$, TMDs ${ }^{9,10,11}$ and awake bruxism ${ }^{12}$.

According to the American Academy of Orofacial Pain, TMDs are defined as a set of disorders involving the masticatory muscles, temporomandibular joint (TMJ) and associated structures ${ }^{13}$.

The etiology of TMDs is considered to be multifactorial and their natural course remains unclear. It is believed that there are risk factors that contribute towards their onset or towards perpetuation of the pain ${ }^{13}$. One of these factors is sleep bruxism, which is defined as repetitive jaw-muscle activity characterized by clenching or grinding of the teeth and/or by bracing or thrusting of the mandible ${ }^{14}$.

Bruxism is a condition of great interest for researchers and clinicians in the fields of dentistry and medicine. It has two circadian manifestations, i.e. it can occur either during sleep or during wakefulness ${ }^{15}$. However, it can also be manifested during both of these periods ${ }^{15,16}$.

Awake bruxism is defined as unawareness of jaw clenching. Its prevalence is reported to be $20 \%$ among the adult population. The physiology and pathology of awake bruxism is unknown, although stress and anxiety are considered to be risk factors. During sleep, awareness of tooth grinding (as noted by a sleep partner or family members) is reported by $8 \%$ of the population ${ }^{17}$.

It has been found that sleep bruxism alone does not increase the risk of having any primary headache, but when associated with TMDs the odds of having chronic migraine, episodic migraine, or episodic tension-type headache are significantly increased ${ }^{18}$. However, there is still much controversy between studies attempting to assess the association between individuals with TMD complaints and sleep bruxism ${ }^{19}$.

Some studies have shown that individuals with masticatory muscle pain have greater frequencies of high and low intensity daytime episodes of headaches ${ }^{20}$. The presence of primary headache was associated with complaints of myofascial pain, dental contacts (more frequent and intense) and muscle tension ${ }^{21}$.

Headache is also a frequent complaint among patients with TMDs ${ }^{18,19,20,21,22}$.
Pericranial myofascial nociception is probably important in relation to the pathophysiology of frequent episodic tension-type headache, whereas sensitization of central nociceptive pathways seems to be responsible for conversion of episodic headache to chronic tension-type headache ${ }^{22}$.

The objective of the present study was to assess the selfreported presence of bruxism and anxiety symptoms among military firefighters with and without frequent episodic tension-type headache and TMDs, compared with controls.

\section{Participants}

This study was approved by the Ethics Committee for Research on Human Beings of the Medical School of the Fluminense Federal University, and the approval was filed under number \#1341316.

The study was conducted within the Military Firefighters' Department of the State of Rio de Janeiro, from December 1, 2015 to April 26, 2016.

The sample was made up through spontaneous demand from firefighters who sought treatment at the Orofacial Pain Clinic at the General Command Headquarters of the Military Fire Brigade of the State of Rio de Janeiro. In total, 162 individuals participated in this study. Each of the individuals who took part in the survey read and signed a free and informed consent statement. There was no external financing source for this study.

\section{METHODS}

A total of 285 individuals between the ages of 18 and 55 years were examined and 125 were excluded through the following criteria: loss of more than two posterior teeth, except third molars $(n=11)$; presence of a total or partial prosthesis $(n=24)$; presence of toothache or neuropathic pain $(n=3)$; continuous treatment of psychiatric disorders, major rheumatological or neurological or chronic pain syndrome $(n=31)$; presence of other headaches $(n=42)$; diagnosis or signs and symptoms compatible with other sleep disorders $(n=5)$; and the impossibility of regular monitoring by their presence at all assessment visits $(n=9)$.

A standardized protocol test was applied to all patients equally by a single experienced and trained dentist using the following diagnostic tools: anamnesis, medical and dental history and physical examination in accordance with standardized clinical records. Through this, the main complaint, pain characteristics (location, intensity, quality, duration, worsening period, mitigating factors and aggravating factors), the presence of headache and pain in other parts of the body and the patient's medical history were detailed.

The evaluation of frequent episodic tension-type headache was performed by a single neurologist through a questionnaire containing objective questions that were in line with the diagnostic criteria established through the 
International Classification of Headache Disorders, third edition (beta version) ${ }^{4}$.

The individuals diagnosed with frequent episodic tension-type headache presented with the following: at least 10 episodes of headache per month, occurring on 1-14 days of each month, on average for more than three months; typically being a bilateral presentation; qualitatively described as a pressing or tightening feeling, of mild to moderate intensity; and lasting for periods of minutes to days. The pain did not worsen with routine physical activity and was not associated with nausea, but photophobia or phonophobia could be present ${ }^{4}$.

TheResearchDiagnostic CriteriaforTemporomandibular Disorders (RDC/TMD) system ${ }^{23}$, Portuguese version ${ }^{24}$, was applied only once to classify TMDs. The RDC/TMD is a standardized system that can be used to classify the most common subtypes of TMD through a questionnaire and a physical examination. Based on Axis I of the RDC/TMD, the patients were classified into three groups: group I (muscle disorders); group 2 (disc displacements); and group 3 (arthralgia, arthritis and arthrosis). Subsequently, the patients were reassigned into two other classifications: individuals with complaints of painful TMDs (comprising the patients in group I, with TMDs caused by myofascial pain with or without limited opening; and/or those in group 3, with TMJ arthralgia and/or osteoarthritis); and individuals without complaints of painful TMDs (comprising only the patients with a group 2 diagnosis, i.e. disc displacement with or without reduction or absence of TMDs). During an evaluation on masticatory muscle sensitivity, the patients confirmed that the pain caused in this evaluation was similar to the pain that they had reported..$^{25}$ The masseter and temporal muscles and the joint capsules were examined manually to assess sensitivity. A standard pressure of $1 \mathrm{~kg}$ was applied to the extra-oral muscles and $0.5 \mathrm{~kg}$ to the joints. ${ }^{23}$ The examiner was calibrated by means of a digital electronic scale. This balance was set to zero and a digital pressure of $1 \mathrm{~kg}$ was applied to its plate. The individuals who reported having sensitivity in their masticatory muscles and joint capsules with intensity of at least 3 over the last month were considered to have painful TMDs.

\section{Assessment of sleep bruxism}

The diagnosis of sleep bruxism was made in two stages: application of a questionnaire and a physical examination. The questionnaire for sleep bruxism was based on the International Classification of Sleep Disorders, third edition ${ }^{26}$ and included three questions about the presence or absence of transient morning jaw muscle pain or fatigue, temporal headache and jaw-locking upon awakening.

This assessment consisted of systematic evaluation of signs and symptoms of sleep bruxism in terms of the following:

- Frequency of days of self-reported sleep bruxism, which was evaluated through five possible choices: $(0)$ none of the time; $(1)<1$ night per month; (2) 1-3 nights per month; (3) 1-3 nights per week; (4) 4-7 nights per week ${ }^{27}$.

- Assessment of abnormal tooth wear, which was observed through an ordinal scale of five points. The incisor, canine and last molar present in the fourth dental quadrant were inspected. Tooth wear was classified on a tooth-bytooth basis using an ordinal scale of five points ${ }^{28}$.

It was considered that patients probably had sleep bruxism when it was self-reported on more than four nights a week and, in addition, these patients presented with: 1) incidence of abnormal tooth wear; or 2) incidence of transient morning jaw muscle pain or fatigue.

For a diagnosis of probable sleep bruxism ${ }^{14}$ to be made, it would need to be impossible to explain the jaw muscle activity in terms of any other current sleep disorder, medical or neurological disorder, medication use, substance use disorder, or use of selective serotonin reuptake inhibitors ${ }^{29}$.

\section{Assessment of awake bruxism}

The Brazilian Portuguese translation of the RDC/TMD ${ }^{23,24}$ questionnaire was also used in ascertaining possible diagnoses of awake bruxism. Individuals received the diagnosis of self-reported awake bruxism if they answered "yes" to $\mathrm{RDC} / \mathrm{TMD}$ question 15d: "During the day, do you grind your teeth or clench your jaw?" Presence of daytime clenching was taken to be a positive response.

\section{Assessment of anxiety symptoms}

Anxiety symptoms were assessed using the Beck Anxiety Inventory ${ }^{30}$. This instrument features 21 items that somatically, emotionally and cognitively reflect these symptoms. It is used to measure the severity of an individual's anxiety. The instrument consists of a self-report questionnaire with 21 multiple-choice questions about how the individual has felt over the last week, expressed in terms of common anxiety symptoms. Each symptom item has four possible response options, as follows, with the corresponding scores: not at all (0); mildly but it didn't bother me much (1); moderately, and it wasn't pleasant at times (2); and severely, and it bothered me a lot (3). The values for each item are summed to produce a total score for all 21 symptoms that can range from 0 to 63 points, and higher values mean higher levels of anxiety symptoms. A mean score of 16-25 points was considered to represent moderate anxiety, i.e. a level of anxiety for which the need for treatment was indicated.

For statistical analysis, the SPSS statistics package for Windows (version 20.0, IBM Corp., Armonk, NY, USA) was used. A logistic regression model was used to calculate odds ratios as a relative measurement of risk. Descriptive statistics and frequency counts were used to characterize the sample. Tests were considered statistically significant when the p-value was $<0.05$. 


\section{RESULTS}

In total, 162 individuals participated in this study. Their median age was 38 years (IQR: 16 years); 86 patients were females $(53.1 \%)$ and 76 were males $(46.9 \%)$.

Four groups were formed and are shown in Table 1. The first group comprised patients with frequent episodic tension-type headache and with non-painful TMDs (G1, $\mathrm{n}=18$ ); the second group comprised patients without frequent episodic tension-type headache or painful TMDs (pain-free controls, $\mathrm{n}=72$ ); the third group included patients with frequent episodic tension-type headache and with painful TMDs $(n=63)$ and the fourth group comprised patients without frequent episodic tension-type headache and with painful TMDs ( $\mathrm{n}=9)$.

The reference value considered to cause damage to the probable sleep bruxism activity was the presence of selfreports with a frequency of 4-7 days per week (Table 1).

The median age at diagnosis was not different comparing all groups tested (independent-samples KruskalWallis test, $p=0.102$ ). In addition, sex, educational level and presence of sleep bruxism were not associated with specific groups ( $\chi^{2}$ test, $\left.p>0.05\right)$. However, the presence of sleep bruxism + awake bruxism and abnormal tooth wear were significantly associated with specific groups. Group 4 consisted of only nine individuals and, for this reason; it was not taken into account for the remaining analysis. Awake bruxism was quite common among headache patients (Table 2) and anxiety levels ranging from moderate to severe were found in patients from the third group (Tables 1 and 3).

Logistic regression analysis showed that independent risk factors for developing frequent episodic tension-type associated with painful TMDs were moderate/severe anxiety levels and awake bruxism (Table 4). However, only awake bruxism was an independent risk factor for developing frequent episodic tension-type headache with nonpainful TMDs.

The Figure shows the distribution of the presence of selfreports of sleep bruxism, awake bruxism and both sleep bruxism + awake bruxism between the groups. Awake bruxism was correlated with women complaining of headache. Sleep bruxism in females was higher in group 3 and, in males, we observed that the control group had more reports of sleep bruxism. The presence of awake bruxism + sleep bruxism was correlated with women in group 3.

Table 1. Demographic characteristics of the groups $(n=162)$.

\begin{tabular}{|c|c|c|c|c|c|c|}
\hline Variable & Category & $\mathrm{G} 1(n=18)$ & $\mathrm{G} 2(n=72)$ & G3 $(n=63)$ & $\mathrm{G} 4(n=9)$ & $c^{2}$ \\
\hline \multirow{2}{*}{ Sex } & Male & 7 & 38 & 25 & 6 & \multirow{2}{*}{$p=0.241$} \\
\hline & Female & 11 & 34 & 38 & 3 & \\
\hline \multirow{3}{*}{ Age } & $18-45$ & 16 & 59 & 45 & 6 & \multirow{3}{*}{$p=0.458$} \\
\hline & $46-50$ & 1 & 10 & 10 & 2 & \\
\hline & $51-55$ & 1 & 3 & 8 & 1 & \\
\hline \multirow{2}{*}{ Educational level } & Undergraduate & 10 & 31 & 39 & 7 & \multirow{2}{*}{$p=0.068$} \\
\hline & High school & 8 & 41 & 24 & 2 & \\
\hline \multirow{2}{*}{ Sleep bruxism } & Present & 1 & 8 & 15 & 2 & \multirow{2}{*}{$p=0.119$} \\
\hline & Absent & 17 & 64 & 48 & 7 & \\
\hline \multirow{2}{*}{ Awake bruxism } & Present & 11 & 6 & 33 & 9 & \multirow{2}{*}{$p<0.0005$} \\
\hline & Absent & 7 & 66 & 30 & 0 & \\
\hline \multirow{2}{*}{ Sleep bruxism and Awake bruxism } & Present & 1 & 4 & 15 & 2 & \multirow{2}{*}{$p=0.011$} \\
\hline & Absent & 17 & 68 & 48 & 7 & \\
\hline \multirow{5}{*}{$\begin{array}{l}\text { Frequency of days of self-reported } \\
\text { sleep bruxism }\end{array}$} & 0 & 4 & 28 & 18 & 0 & \multirow{5}{*}{$p=0.002$} \\
\hline & 1 & 4 & 21 & 11 & 1 & \\
\hline & 2 & 5 & 14 & 15 & 3 & \\
\hline & 3 & 4 & 1 & 4 & 3 & \\
\hline & 4 & 1 & 8 & 15 & 2 & \\
\hline \multirow{5}{*}{ Abnormal tooth wear } & 0 & 2 & 27 & 15 & 0 & \multirow{5}{*}{$p=0.001$} \\
\hline & 1 & 13 & 35 & 29 & 6 & \\
\hline & 2 & 3 & 4 & 19 & 1 & \\
\hline & 3 & 0 & 5 & 0 & 2 & \\
\hline & 4 & 0 & 1 & 0 & 0 & \\
\hline \multirow{2}{*}{ Beck Anxiety Inventory* } & $0-15$ & 18 & 71 & 47 & 7 & \multirow{2}{*}{$p<0.0005$} \\
\hline & $16-31$ & 0 & 1 & 16 & 2 & \\
\hline
\end{tabular}

G1: individuals with frequent episodic tension-type headache and with non-painful TMDs; G2: control group; G3: with frequent episodic tension-type headache and with painful TMDs; G4: without frequent episodic tension-type headache and with painful TMDs. 
Table 2. Evaluation of the presence of self-reported sleep bruxism, awake bruxism and both of these together in the groups.

\begin{tabular}{|c|c|c|}
\hline Groups & Presence of $A B n(\%)$ & OR $(95 \% \mathrm{Cl})$ \\
\hline G2 & $6(8.3 \%)$ & $0.03(0.01-0.15 ; p<0.0005)$ \\
\hline G1 & $11(61.1 \%)$ & $4.87(1.69-14.01 ; p=0.003)$ \\
\hline \multirow[t]{2}{*}{ G3 } & $33(52.4 \%)$ & $2.18(1.01-4.73 ; p=0.049)$ \\
\hline & Presence of SB n (\%) & OR (95\% Cl) \\
\hline G2 & $8(11.1 \%)$ & $\left(0-1.8 \times 10^{30} ; p=0.999\right)$ \\
\hline G1 & $1(5.5 \%)$ & $\left(0-1.8 \times 10^{30} ; p=0.999\right)$ \\
\hline \multirow[t]{2}{*}{ G3 } & $15(23.8 \%)$ & $\left(0-1.8 \times 10^{30} ; p=0.999\right)$ \\
\hline & Presence of AB + SB n (\%) & OR $(95 \% \mathrm{Cl})$ \\
\hline G2 & $4(5.5 \%)$ & $\left(0-1.8 \times 10^{30} ; p=0.999\right)$ \\
\hline G1 & $1(5.5 \%)$ & $\left(0-1.8 \times 10^{30} ; p=0.999\right)$ \\
\hline G3 & $15(23.8 \%)$ & $\left(0-1.8 \times 10^{30} ; p=0.999\right)$ \\
\hline
\end{tabular}

AB: awake bruxism; SB: sleep bruxism; Cl:confidence interval; OR: odds ratio; G1: individuals with frequent episodic tension-type headache and with non-painful TMDs; G2: control group; G3: with frequent episodic tension-type headache and with painful TMDs.

Table 3. Evaluation of the presence of anxiety symptoms among the groups ( $n=162)$.

\begin{tabular}{lcccc}
\hline Anxiety levels & G1 $n(\%)$ & G2 n (\%) & G3 n (\%) & G4 n (\%) \\
\hline Minimal & $14(77.8 \%)$ & $57(79.1 \%)$ & $21(33.3 \%)$ & $5(55.5 \%)$ \\
Mild & $4(22.2 \%)$ & $14(19.5 \%)$ & $26(41.3 \%)$ & $2(22.3 \%)$ \\
Moderate & 0 & $1(1.4 \%)$ & $14(22.2 \%)$ & $1(11.1 \%)$ \\
Severe & 0 & 0 & $2(3.2 \%)$ & $1(11.1 \%)$ \\
Total & $18(100 \%)$ & $72(100 \%)$ & $63(100 \%)$ & $9(100 \%)$ \\
\hline
\end{tabular}

G1: individuals with frequent episodic tension-type headache and with non-painful TMDs; G2: control group; G3: with frequent episodic tension-type headache and with painful TMDs; G4: without frequent episodic tension-type headache and with painful TMDs.

Table 4. Logistic regression analysis.

\begin{tabular}{|c|c|c|c|c|c|}
\hline \multirow{2}{*}{ Variable } & \multirow{2}{*}{ Category } & \multicolumn{2}{|l|}{ G1 } & \multicolumn{2}{|l|}{ G3 } \\
\hline & & OR $(95 \% \mathrm{Cl})$ & $p$-value & OR $(95 \% \mathrm{Cl})$ & $\mathrm{p}$-value \\
\hline Beck Anxiety Inventory & Moderate/severe (16-31) & - & - & $7.61(2.02-26.67)$ & 0.003 \\
\hline Awake bruxism & Present & $3.14(1.15-8.62)$ & 0.026 & $2.11(1.02-4.33)$ & 0.043 \\
\hline
\end{tabular}

G1, individuals with frequent episodic tension-type headache and with non-painful TMDs; G3, with frequent episodic tension-type headache and with painful TMDs.

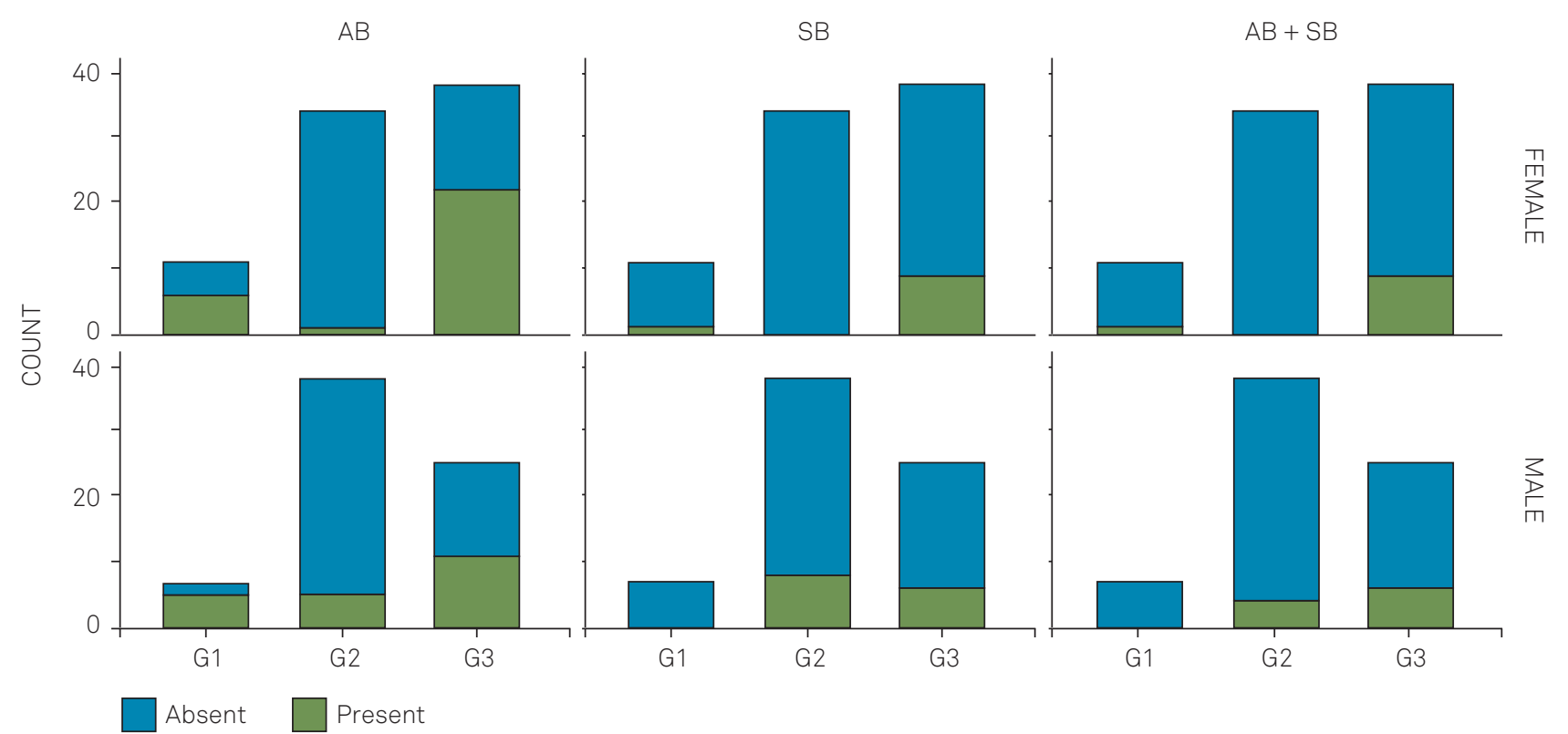

Figure. Distribution of the presence of self reports of sleep bruxism (SB), awake bruxism (AB) and both (SB + AB) between the groups. 


\section{DISCUSSION}

The largest number of diagnoses of sleep bruxism through self-reports and clinical examination occurred in group 3 (Table 2). This group comprised individuals with complaints of tension-type headache and painful TMDs (Table 1).

The results found that sleep bruxism as an isolated diagnosis without the presence of painful TMDs, did not present a risk of developing primary headache, as previously mentioned by another group of researchers ${ }^{18}$.

The highest dental wear scores were in the controls (group 2). Assessing tooth wear requires some comments. The age group is an important factor because there is natural physiological wear. The presence of a diet rich in acidic foods and beverages should be taken into consideration. Then the dental wear factor should be observed in the construction of a diagnosis within the patient's medical history.

In studying sleep bruxism, it is very important to report the individuals' ages. The prevalence of sleep bruxism is high among young individuals and decreases after the age of 50 years $^{17}$. Groups 2 and 3 had mean ages that were comparable with those of previous studies (Table 1).

Parafunctional habits such as clenching or grinding (bruxism) during the daytime and at night are considered to have a great impact on the etiopathogenesis of TMDs ${ }^{16}$.

There is much controversy surrounding studies that have attempted to assess the association between individuals with TMD complaints and sleep bruxism ${ }^{19}$. Studies in which polysomnographic examinations were used as the gold-standard diagnostic method have failed to demonstrate this association $^{19}$. However, studies conducted with larger samples without polysomnography that used questionnaires and/or clinical tests to diagnose the presence of possible or probable sleep bruxism have verified that an association between sleep bruxism and TMD exists. This was found especially when the concomitant presence of awake bruxism was observed ${ }^{16,18,19,20}$.

Although the evidence is currently inconclusive and does not provide information on the type of bruxism during sleep or during wakefulness, it is possible to suggest that bruxism may be associated with TMDs. ${ }^{19}$

The self-reported presence of awake bruxism was associated with the groups comprising headache patients (Table 2). These results are concordant with those of other studies $^{18,19,20,21,22}$ that found that awake bruxism occurred predominantly among women (in the case of frequent episodic tension-type headache, slight predominance ${ }^{5}$ ) with a mean age range of 30 to 40 years, with complaints of headache and muscle pain.
Some studies ${ }^{6,18,19,20,21,22}$ have found that the interactions between primary headaches and the presence of TMD symptoms were greater when pain in the masticatory muscles was present.

However, in our study, only awake bruxism was an independent risk factor for developing frequent episodic tensiontype headache with non-painful TMDs (Table 4).

Increased frequency of both high and low-intensity diurnal tightening episodes was correlated with masticatory muscle pain. Clinicians need to recognize that the frequency and intensity of daytime clenching are noticeably greater among individuals with masticatory muscle pain. With this knowledge, it will be possible to better tailor treatments ${ }^{20}$.

Self-reported bruxism activity (i.e. situations in which individuals agreed that they ground their teeth) was related to the presence of frequent episodic tension-type headache and painful TMDs (Table 2).

Analysis on subjective anxiety symptoms showed that there was an association between group 3 and symptoms of moderate and severe levels of anxiety. In addition, the symptoms of anxiety were correlated with the presence of headaches $^{7,8,9}$, TMDs $^{9,10,11}$ and awake bruxism ${ }^{12}$.

Anxiety complaints are common in the general population and especially in studies conducted among military firefighters ${ }^{1,2,3}$. However, in group 2, comprising firefighters without any complaint of pain, this association was not found.

The present study had some limitations. The sample consisted of patients who sought treatment for TMDs and the results are not representative of the general population. Laboratory sleep assessment is required to establish a definitive diagnosis of sleep bruxism, but for large samples this would be expensive and inaccessible. On the other hand, the methodology of the present study had some important strengths. Headache and TMDs were diagnosed and classified in accordance with the "gold standard" of the RDC/TMD ${ }^{23}$ and International Classification of Headache Disorders-III ${ }^{4}$.

In conclusion, the study showed that both anxiety and awake bruxism were risk factors for the development of frequent episodic tension-type headache associated with painful TMD. On the other hand, only awake bruxism was an independent risk factor for developing frequent episodic tension-type headache with non-painful TMDs.

\section{Acknowledgments}

We thank the Military Fire Brigade of the State of Rio de Janeiro for its support. 
1. Lusa S, Miranda H, Luukkonen R, Punakallio A. Sleep disturbances predict long-term changes in low back pain among Finnish firefighters: 13-year follow-up study. Int Arch Occup Environ Health. 2015 Apr;88(3):369-79. https://doi.org/10.1007/s00420-014-0968-z

2. Marconato RS, Monteiro MI. Pain, health perception and sleep: impact on the quality of life of firefighters/rescue professionals. Rev Lat Am Enfermagem. 2015 Nov-Dec;23(6):991-9. https://doi.org/10.1590/0104-1169.0563.2641

3. Kim MG, Seo JI, Kim K, Ahn YS. Nationwide firefighter survey: the prevalence of lower back pain and its related psychological factors among Korean firefighters. Int J Occup Saf Ergon. 2017 Dec;23(4):447-56. https://doi.org/10.1080/10803548.2016.1219149

4. Headache Classification Committee of the International Headache Society (IHS). The international classification of headache disorders, 3rd edition (beta version). Cephalalgia. 2013 Jul;33(9):629-808. https://doi.org/10.1177/0333102413485658

5. Queiroz LP, Silva Junior AA. The prevalence and impact of headache in Brazil. Headache. 2015 Feb;55 Suppl 1:32-8. https://doi.org/10.1111/head.12511

6. Silva Juniorr AA, Brandão KV, Faleiros BE, Tavares RM, Lara RP, Januzzi E, et al. Temporo-mandibular disorders are an important comorbidity of migraine and may be clinically difficult to distinguish them from tension-type headache. Arq Neuropsiquiatr. 2014;72(2):99-103. https://doi.org/10.1590/0004-282X20130221

7. Lampl C, Thomas H, Tassorelli C, Katsarava Z, Laínez JM, Lantéri-Minet M, et al. Headache, depression and anxiety: associations in the Eurolight project. J Headache Pain. 2016;17(1):59. https://doi.org/10.1186/s10194-016-0649-2

8. Lucchetti G, Peres MF, Lucchetti AL, Mercante JP, Guendler VZ, Zukerman E. Generalized anxiety disorder, subthreshold anxiety and anxiety symptoms in primary headache. Psychiatry Clin Neurosci. 2013 Jan;67(1):41-9. https://doi.org/10.1111/j.1440-1819.2012.02405.x

9. Vazquez-Delgado E, SchmidtJE, Carlson CR, Leeuw Rd, Okeson JP. Psychological and sleep quality differences between chronic daily headache and temporomandibular disorders patients. Cephalalgia. 2004Jun;24(6):446-54. https://doi.org/10.1111/j.1468-2982.2004.00698.x

10. Reissmann DR, John MT, Seedorf H, Doering S, Schierz O. Temporomandibular disorder pain is related to the general disposition to be anxious. J Oral Facial Pain Headache. 2014;28(4):322-30. https://doi.org/10.11607/ofph.1277

11. Reiter S, Emodi-Perlman A, Goldsmith C, Friedman-Rubin P, Winocur E. Comorbidity between depression and anxiety in patients with temporomandibular disorders according to the research diagnostic criteria for temporomandibular disorders. J Oral Facial Pain Headache. 2015;29(2):135-43. https://doi.org/10.11607/ofph.1297

12. Endo H, Kanemura K, Tanabe N, Takebe J. Clenching occurring during the day is influenced by psychological factors.J Prosthodont Res. 2011 Jul;55(3):159-64. https://doi.org/10.1016/j.jpor.2010.11.003

13. Leeuw R. Orofacial pain: guidelines for assessment, diagnosis, and management. 4th ed. Chicago: Quintessence; 2008.

14. Lobbezoo F, Ahlberg J, Glaros AG, Kato T, Koyano K, Lavigne GJ, et al. Bruxism defined and graded: an international consensus.J Oral Rehabil. 2013 Jan;40(1):2-4. https://doi.org/10.1111/joor.12011

15. Oporto GH 5th, Bornhardt T, Iturriaga V, Salazar LA. Genetic polymorphisms in the serotonergic system are associated with circadian manifestations of bruxism. J Oral Rehabil. 2016 Nov;43(11):805-12. https://doi.org/10.1111/joor.12436
16. Sierwald I, John MT, Schierz O, Hirsch C, Sagheri D, Jost-Brinkmann $P G$, et al. Association of temporomandibular disorder pain with awake and sleep bruxism in adults. J Orofac Orthop. 2015 Jul;76(4):305-17. https://doi.org/10.1007/s00056-015-0293-5

17. Lavigne GJ, Khoury S, Abe S, Yamaguchi T, Raphael K. Bruxism physiology and pathology: an overview for clinicians. J Oral Rehabil. 2008 Jul;35(7):476-94. https://doi.org/10.1111/j.1365-2842.2008.01881.x.

18. Fernandes G, Franco AL, Gonçalves DA, Speciali JG, Bigal ME, Camparis CM. Temporomandibular disorders, sleep bruxism, and primary headaches are mutually associated. J Orofac Pain. 2013;27(1):14-20. https://doi.org/10.11607/jop.921

19. Jiménez-Silva A, Peña-Durán C, Tobar-Reyes J, Frugone-Zambra R. Sleep and awake bruxism in adults and its relationship with temporomandibular disorders: A systematic review from 2003 to 2014. Acta Odontol Scand. 2017 Jan;75(1):36-58. https://doi.org/10.1080/00016357.2016.1247465

20. Cioffi I, Landino D, Donnarumma V, Castroflorio T, Lobbezoo F, Michelotti A. Frequency of daytime tooth clenching episodes in individuals affected by masticatory muscle pain and pain-free controls during standardized ability tasks. Clin Oral Investig. 2017 May;21(4):1139-48. https://doi.org/10.1007/s00784-016-1870-8

21. Glaros AG, Urban D, Locke J. Headache and temporomandibular disorders: evidence for diagnostic and behavioural overlap. Cephalalgia. 2007 Jun;27(6):542-9. https://doi.org/10.1111/j.1468-2982.2007.01325.x

22. Graff-Radford SB. Temporomandibular disorders and headache. Dent Clin North Am. 2007 Jan;51(1):129-44. https://doi.org/10.1016/j.cden.2006.09.005

23. Dworkin SF, LeResche L. Research diagnostic criteria for temporomandibular disorders: review, criteria, examinations and specifications, critique. J Craniomandib Disord. 1992;6(4):301-55.

24. Pereira Júnior FJ, Favilla EE, Dworkin S, Huggins K. Critérios de diagnóstico para pesquisa das disfunções temporomandibulares (RDC/TMD): tradução oficial para a língua portuguesa.J Bras Clin Odontol Integ. 2004;8(47):384-95.

25. Schiffman EL, Ohrbach R, Truelove EL, et al. The research diagnostic for temporomandibular disorders. V: methods used to establish and validate revised Axis I diagnostic algorithms. J Orofac Pain. 2010;24(1):63-78.

26. American Academy of Sleep Medicine. International classification of sleep disorders. 3rd ed. Darien (IL): American Academy of Sleep Medicine; 2014.

27. Stuginski-Barbosa J, Porporatti AL, Costa YM, Svensson P, Conti PC. Agreement of the international classification of sleep disorders criteria with polysomnography for sleep bruxism diagnosis: a preliminary study. J Prosthet Dent. 2017 Jan;117(1):61-6. https://doi.org/10.1016/j. prosdent.2016.01.035

28. Lobbezoo F, Naeije M. A reliability study of clinical tooth wear measurements. J Prosthet Dent. 2001 Dec;86(6):597-602. https://doi.org/10.1067/mpr.2001.118892

29. Lobbezoo F, van Denderen RJ, Verheij JG, Naeije M. Reports of SSRI-associated bruxism in the family physician's office. J Orofac Pain. 2001;15(4):340-6.

30. Beck AT, Epstein N, Brown G, Steer RA. The beck anxiety inventory. J Consult Clin Psychol. 1988 Dec;56(6):893-7. https://doi.org/10.1037/0022-006X.56.6.893 